\title{
Analisis Efektivitas Mesin Batching Plant 1 dan Mesin Batching Plant 2 dengan Overall Equipment Effectiveness Pada PT. X
}

\author{
Nia Budi Puspitasari* dan Eldinda Sazida Permatasari \\ Program Studi Teknik Industri, Universitas Diponegoro \\ Jalan Prof Sudharto, Tembalang, Semarang, Indonesia
}

\begin{abstract}
Overall Equipment Effectiveness (OEE) is one of Total Productive Maintenance (TPM) application program, which aims to determine the effectiveness of a machine. PT. X has 3 machine batching plant where machine 1 and 2 used effectively, from the data historically known that the machines batching plant 1 having a value greater namely 1030 minutes compared to the engine batching plant 2 that have value 240 minutes. This research measures the OEE value of two machines Bactching Plant and then compares the results. The value obtained is $82.71 \%$ for machine 1 and $84.83 \%$ for machine 2. This research suggests that the performance factor is the biggest problem in the machine OEE values, because the enterprise systems is make to order, the recommended action is to maximize the production capacity of each machine by considering a more accurate production targets in each period.
\end{abstract}

Keywords: batching plant, machine, overall equipment effectivenesss, total productive maintenance

\section{Pendahuluan}

Dalam era globalisasi, banyak perusahaan yang mengalami perkembangan teknologi dan informasi. Untuk dapat bertahan, perusahaan harus mampu menerapkan kebijakan tertentu yang sesuai dengan perkembangan sehingga mampu bersaing dan tetap memberikan pelayanan yang memuaskan kepada konsumen. Salah satu permasalahan yang dihadapi oleh divisi produksi adalah bagaimana melaksanakan proses produksi seefisien dan seefektif mungkin. Fungsi pemeliharaan bukanlah suatu pemborosan tetapi merupakan suatu investasi dalam sistem manufaktur yang maju (Mulyati,2011).

Usaha perbaikan pada industri manufaktur, dilihat dari segi peralatan adalah dengan meningkatkan efetivitas mesin/peralatan yang ada seoptimal mungkin. Pada prakteknya, seingkali usaha perbaikan yang dilakukan tersebut hanya pemborosan, karena tidak menyentuh akar permasalahan yang sesungguhnya. Hal ini disebabkan karena tim perbaikan tidak mengetahui dengan jelas permasalahan yang terjadi dan faktor-faktor yang menyebabkan permasalahan tersebut. Untuk itu diperlukan suatu metode yang mampu mengungkap masalah yang ada dengan jelas agar dapat dilakukan peningkatan kinerja dengan optimal (Hasriyono, 2009).

Salah satu pendekatan yang dapat digunakan adalah Total Productive Maintenance (TPM). Menurut Corder, (1992) TPM tidak hanya terfokus bagaimana mengoptimalkan produktivitas dari peralatan atau material pendukung kegiatan kerja, tetapi juga memperhatikan bagaimana meningkatkan produktivitas dari para pekerja atau operator yang nantinya akan memegang kendali pada peralatan dan material tersebut. TPM dengan menggunakan metode Overall Equipment Effectiveness (OEE) berfungsi untuk melihat secara keseluruhan kondisi lini dan efektivitas yang mencakup tiga faktor yaitu avaibility rate, performance rate dan rate of quality. Melalui TPM dengan menggunakan metode OEE serta pengaplikasian delapan pilar akan mampu menjaga fungsi dari peralatan atau material pendukung kegiatan kerja. Memperhatikan

\footnotetext{
*Correspondance : niabudipuspitasari@gmail.com
} 
bagaimana meningkatkan produktivitas dari para pekerja atau operator yang nantinya akan memegang kendali secara langsung pada peralatan dan material tersebut.

PT X merupakan perusahaan produksi beton berskala besar dengan menggunakan mesinmesin canggih. Jalur untuk membuat beton dibagi menjadi dua yaitu jalur putar dan jalur non putar. Jalur putar digunakan untuk memproduksi beton yang didesain dengan rongga di tengahnya seperti tiang pancang, sedangkan jalur non putar digunakan untuk memproduksi beton yang tidak berongga seperti bantalan rel.

Mesin yang digunakan untuk membuat produk beton adalah batching plant yang digunakan untuk mencampur bahan pembuat beton, hopper yang digunakan untuk mengangkut adonan beton ke cetakan, hoist yang digunakan untuk mengangkat produk beton ke mesin spinning, dan mesin spinning yang digunakan untuk perataan, pembentukan dan pemadatan beton. Mesinmesin yang dimiliki perusahaan sering mengalami kendala dalam masalah efektifitas kerja mesin terutama mesin batching plant yang merupakan mesin yang paling penting dalam memproduksi beton. Apabila mesin batching plant mengalami kerusakan maka produktifias menurun. Untuk menghindarinya perusahaan menerpakan preventive maintenance, yaitu perawatan secara berkala.

Pada PT X terhadap 3 mesin Batching plant yang terdapat pada Plan 1-2, 4, dan 5-6. Batching plant yang efektif digunakan adalah pada plan 1-2 serta 5-6, karena jalur 4 masih dalam masa percobaan. Dari data historis pada Tabel 1, mesin Batching plant jalur 1-2 dan 5-6, mesin Batching plant jalur 1-2 lebih sering mengalami kerusakan.

Tabel 1 Data Downtime Mesin Batching plant

\begin{tabular}{ccc}
\hline Periode & \multicolumn{2}{c}{ Downtime } \\
\cline { 2 - 3 } & Mesin 1 & Mesin 2 \\
\hline Juli & 120 & 240 \\
\hline Agustus & 195 & 0 \\
\hline September & 430 & 0 \\
\hline Oktober & 210 & 0 \\
\hline November & 75 & 0 \\
\hline Desember & 0 & 0 \\
\hline TOTAL & 1030 & 240 \\
\hline
\end{tabular}

Untuk itu penelitian ini akan melakukan perbandingan efektifitas antara mesin Batching plant jalur 1-2 dan 5-6 dengan analisis mengenai efektifitas mesin menggunakan metode $O E E$. Tujuan dari penelitian ini adalah melakukan pengukuran OEE pada mesin dan menganalisa perbandingan efektivitas OEE antara mesin Batching plant jalur 1 dan 2.

\section{Metode Penelitian}

Metodologi penelitian merupakan tahap - tahap penelitian yang harus diterapkan terlebih dahulu sebelum melakukan pemecahan terhadap permasalahan yang ada sehingga penelitian dapat dilakukan dengan terarah.

\subsection{Penelitian Pendahuluan}

Penelitian pendahuluan dilakukan untuk mengidentifikasi permasalahan apa yang sedang dihadapi oleh pihak perusahaan, yaitu dengan melakukan wawancara langsung dengan Departemen Teknik dan Mutu PT. X. 


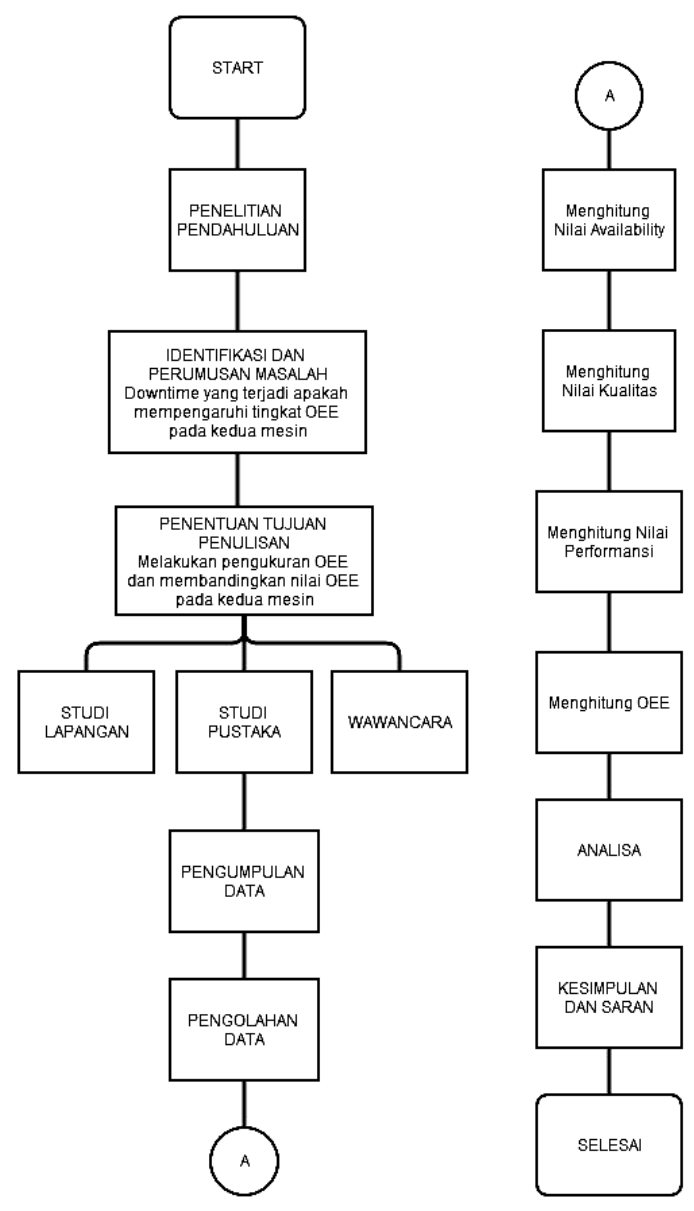

Gambar 1. Metodologi Penelitian

\subsection{Identifikasi Masalah}

Dengan melakukan penelitian pendahuluan melalui wawancara dan pengamatan secara langsung di lantai produksi PT. X maka didapatkan mesin Batching Plant merupakan mesin utama dalam pembuatan Beton, maka untuk mengetahui ke efektifan mesin tersebut dilakukan perhitungan $O E E$.

\subsection{Tujuan Penelitian}

Tujuan penelitian yang hendak dicapai untuk permasalahan yang sedang terjadi pada PT. X adalah melakukan pengukuran OEE pada mesin dengan menggunakan data penelitian dan melakukan perbandingan efektivitas OEE antara mesin Batching Plant jalur 1-2 dan 5-6.

\subsection{Studi Lapangan}

Studi lapangan dilakukan untuk mengetahui kondisi riil dari perusahaan. Dengan mengamati mesin yang sedang beroperasi sehingga dapat memberikan gambaran kepada penulis mengenai kondisi mesin sehingga dapat membantu mempermudah penulis dalam memahami permasalahan tersebut dan diharapkan dapat memberikan solusi pemecahan masalah yang tepat.

\subsection{Studi Pustaka}

Dalam melakukan penelitian, penulis menggunakan studi pustaka yang dapat menunjang dan memberikan pengetahuan kepada penulis mengenai permasalahan yang sedang dihadapi 
oleh perusahaan sehingga permasalahan tersebut dapat dipecahkan dengan sebaik-baiknya. Dalam studi pustaka ini, penulis membaca buku-buku referensi serta topik-topik yang berkaitan dengan permasalahan. Selain itu. studi pustaka juga digunakan penulis sebagai landasan teori pemecahan masalah.

\subsubsection{Maintenance}

Pemeliharaan merupakan fungsi yang penting dalam suatu pabrik. Sebagai suatu usaha menggunakan fasilitas/ peralatan produksi agar kontinuitas produksi dapat terjamin dan menciptakan suatu keadaan operasi produksi yang memuaskan sesuai dengan rencana. Selain itu, fasilitas/ peralatan tersebut tidak mengalami kerusakan selama dipergunakan sebelum jangka waktu tertentu yang direncanakan tercapai.

Pemeliharaan (maintenance), menurut The American Management Association, Inc. (1971), adalah kegiatan rutin, pekerjaan berulang yang dilakukan untuk menjaga kondisi fasilitas produksi agar dapat dipergunakan sesuai fungsi dan kapasitas sebenarnya secara efisien. Ini berbeda dengan perbaikan. Pemeliharaan (maintenance) juga didefinisikan sebagai suatu kombinasi untuk menjaga suatu barang dalam, atau memperbaikinya sampai suatu kondisi yang diterima (Corder, 1992).

\subsubsection{Preventive Maintenance}

Preventive maintenance adalah suatu sistem perawatan yang terjadual dari suatu peralatan/komponen yang didesain untuk meningkatkan kehandalan mesin serta untuk mengantisipasi segala kegiatan perawatan yang tidak direncanakan sebelumnya (Worsham, 2002).

\subsubsection{Corrective Maintenance}

Corrective maintenance merupakan kegiatan perawatan yang dilakukan untuk mengatasi kegagalan atau kerusakan yang ditemukan selama masa waktu preventive maintenance. Pada umumnya, corrective maintenance bukanlah aktivitas perawatan yang terjadwal, karena dilakukan setelah sebuah komponen mengalami kerusakan dan bertujuan untuk mengembalikan kehandalan sebuah komponen atau sistem ke kondisi semula (Worsham, 2002).

\subsubsection{Total Productive Maintenance}

Total Productive Maintenance merupakan suatu filosofi yang bertujuan memaksimalkan efektivitas dari fasilitas yang digunakan di dalam industri, yang tidak hanya dialamatkan pada perawatan saja tapi pada semua aspek dari operasi dan instalasi, dari fasilitas produksi termasuk juga didalamnya peningkatan motivasi dari orang-orang yang bekerja dalam perusahaan tersebut. Tools dalam TPM adalah teamwork, preventive maintenance, housekeeping, training, Autonomous Maintenance, serta work standardization.

\subsubsection{Overall Equipment Effectiveness}

OEE dipengaruhi oleh tiga faktor yaitu

1. Availability Rate

$\frac{\text { Waktu operasi }}{\text { Waktu tersedia }} \times 100 \%$

\section{Rate of Quality}

$\frac{\text { Jumlah Produksi-Produk Gagal }}{\text { Jumlah Produksi }} \times 100 \%$

\section{Performance rate}


$\frac{\text { Hasil Produksi }}{\text { Target Produksi }} \times 100 \%$

Sedangkan OEE sendiri dihitung dengan perkalian antara ketiga faktor tersebut, dihitung dengan persamaan:

$\mathrm{OEE}=$ Availability Rate $x$ Rate of Quality $\mathrm{x}$ Performance rate

Nilai OEE dari peralatan dalam kondisi ideal yang merupakan standar dari perusahaan kelas dunia adalah 85\% (Dal, 2000). Nilai tersebut dengan komposisi (Betrianis dan Suhendra, 2005):

- Availability Ratio $90 \%$ atau lebih.

- Quality Ratio $99 \%$ atau lebih.

- Performance Ratio 95\% atau lebih.

\subsection{Wawancara}

Salah satu teknik pengumpulan data yang dilakukan oleh penulis adalah dengan melalui wawancara terhadap staff Departemen Peralatan serta kepada operator mesin. Wawancara dengan pihak yang berhubungan langsung dengan permasalahan yang akan dibahas dapat memberikan pengetahuan kepada penulis mengenai perawatan yang dilakukan kepada mesin Batching Plant dan lain sebagainya yang mendukung penulis untuk melakukan pemecahan masalah.

\subsection{Pengumpulan Data}

Pengumpulan data merupakan kegiatan mengumpulkan data yang diperlukan oleh penulis dalam melakukan pemecahan masalah yang sedang dihadapi oleh pihak perusahaan dan datadata lain yang secara tidak langsung menunjang tercapainya tujuan dari kerja praktek ini. Datadata yang dikumpulkan penulis merupakan data primer dan data sekunder.

\subsection{Pengolahan Data}

Pengolahan data yang dilakukan penulis dalam penyusunan laporan kerja praktek ini meliputi :

a. Mengitung Faktor Availability

Faktor Availability dihitung dengan membandingkan waktu operasi yang tersedia dengan waktu operasi yang dapat digunakan.

b. Menghitung Faktor Kualitas

Faktor kualitas dihitung dengan cara membandingkan hasil produksi yang sesuai dengan hasil produksi yang gagal

c. Menghitung Faktor Performansi

Faktor Performansi dihitung dengan cara membandingkan hasil produksi dengan target produksi

d. Menghitung OEE

OEE dihitung dengan mengalikan faktor availability, kualitas, dan performansi

e. Membandingkan OEE mesin Batching Plant jalur 1-2 dan mesin Batching Plant jalur 56

OEE pada kedua mesin dibandingkan, mana yang memiliki OEE lebih besar

\subsection{Kesimpulan dan Saran}

Penutup berisi kesimpulan dan saran. Kesimpulan diberikan berdasarkan pembahasan yang telah dilakukan dan disesuaikan dengan tujuan penelitian. Selain itu juga diberikan saran-saran yang sekiranya dapat bermanfaat dan menjadi bahan pertimbangan bagi pihak perusahaan. 


\section{Hasil dan Pembahasan}

Penelitian dilakukan pada mesin Batching plant 1 dan mesin Batching plant 2 pada periode Juli - Desember 2013.

Availability Rate

Hasil perhitungan availability untuk mesin Batching plant 1 dapat dilihat pada Tabel 2. Availability untuk mesin Batching plant 2 dapat dilihat pada Tabel 3.

Tabel 2 Availability Rate Mesin Batching plant 1

\begin{tabular}{cccc}
\hline Periode & $\begin{array}{c}\text { Waktu operasi } \\
\text { tersedia (menit) }\end{array}$ & $\begin{array}{c}\text { Downtime } \\
\text { (menit) }\end{array}$ & Availability \\
\hline Juli & 18000 & 120 & 0,993333 \\
\hline Agustus & 18000 & 195 & 0,989166 \\
\hline September & 18000 & 430 & 0,976111 \\
\hline Oktober & 18000 & 210 & 0,988333 \\
\hline November & 18000 & 75 & 0,995833 \\
\hline Desember & 18000 & 0 & 1 \\
\hline
\end{tabular}

Tabel 3 Availability Rate Mesin Batching plant 2

\begin{tabular}{cccc}
\hline Periode & $\begin{array}{c}\text { Waktu Operasi } \\
\text { Tersedia (menit) }\end{array}$ & $\begin{array}{c}\text { Downtime } \\
\text { (menit) }\end{array}$ & Availability \\
\hline Juli & 18000 & 240 & 0,9866 \\
\hline Agustus & 18000 & 0 & 1 \\
\hline September & 18000 & 0 & 1 \\
\hline Oktober & 18000 & 0 & 1 \\
\hline November & 18000 & 0 & 1 \\
\hline Desember & 18000 & 0 & 1 \\
\hline
\end{tabular}

Rate of Quality

Perhitungan kualitas untuk mesin Batching plant 1 dapat dilihat pada Tabel 4. Kualitas untuk mesin Batching plant 2 dapat dilihat pada Tabel 5

Tabel 4 Rate of Quality Mesin Batching Plant 1

\begin{tabular}{cccc}
\hline Periode & Produk Gagal $\left(\mathrm{m}^{3}\right)$ & Jumlah Produksi $\left(\mathrm{m}^{3}\right)$ & Kualitas \\
\hline Juli & 3.105 & 2207 & 0,9985 \\
\hline Agustus & 2.138 & 1720 & 0,9987 \\
\hline September & 0 & 2308 & 1 \\
\hline Oktober & 1.464 & 2422 & 0,9993 \\
\hline November & 0 & 2389 & 1 \\
\hline Desember & 0 & 1233 & 1 \\
\hline
\end{tabular}

Tabel 5 Rate of Quality Mesin Batching Plant 2

\begin{tabular}{cccc}
\hline Periode & Produk gagal $\left(\mathrm{m}^{3}\right)$ & Total Produksi $\left(\mathrm{m}^{3}\right)$ & Kualitas \\
\hline Juli & 0 & 804 & 1 \\
\hline
\end{tabular}




\begin{tabular}{cccc}
\hline Agustus & 0 & 447 & 1 \\
\hline September & 0 & 710 & 1 \\
\hline Oktober & 0 & 609 & 1 \\
\hline November & 1 & 767 & 0,9986 \\
\hline Desember & 0 & 793 & 1
\end{tabular}

\section{Performance rate}

Perhitungan Performance rate untuk mesin Batching plant 1 dapat dilihat pada Tabel 6, sedangkan Performance rate untuk mesin Batching plant 2 pada Tabel 7.

Tabel 6 Performance rate Mesin Batching Plant 1

\begin{tabular}{cccc}
\hline Periode & Target Produksi $\left(\mathrm{m}^{3}\right)$ & Hasil Produksi $\left(\mathrm{m}^{3}\right)$ & Performansi \\
\hline Juli & 2447,16 & 2207 & 0,9018 \\
\hline Agustus & 2447,16 & 1720 & 0,7028 \\
\hline September & 2447,16 & 2308 & 0,9431 \\
\hline Oktober & 2447,16 & 2422 & 0,9897 \\
\hline November & 2447,16 & 2389 & 0,9762 \\
\hline Desember & 2447,16 & 1233 & 0,5038 \\
\hline
\end{tabular}

Tabel 7 Performance rate Mesin Batching Plant 2

\begin{tabular}{cccc}
\hline Periode & Target Produksi $\left(\mathrm{m}^{3}\right)$ & Jumlah Produksi $\left(\mathrm{m}^{3}\right)$ & Performansi \\
\hline Juli & 809,05 & 804 & 0,99376 \\
\hline Agustus & 809,05 & 447 & 0,5525 \\
\hline September & 809,05 & 710 & 0,87757 \\
\hline Oktober & 809,05 & 609 & 0,75273 \\
\hline November & 809,05 & 767 & 0,94803 \\
\hline Desember & 809,05 & 793 & 0,98016 \\
\hline
\end{tabular}

Setelah dilakukan perhitungan pada ketiga faktor yaitu Availability Rate, Rate of Quality, dan Performance rate, didapatkan hasil untuk mesin Batching plant 1 dapat dilihat pada Tabel 8 .

Tabel 8 OEE Mesin Batching Plant 1

\begin{tabular}{ccccc}
\hline Periode & Availbility & Quality & Performance & OEE \\
\hline Juli & 0,9933 & 0,9985 & 0,9018 & 0,8945 \\
\hline Agustus & 0,9891 & 0,9987 & 0,7028 & 0,6943 \\
\hline September & 0,9761 & 1 & 0,9431 & 0,9206 \\
\hline Oktober & 0,98833 & 0,9994 & 0,9897 & 0,9775
\end{tabular}

Mesin Batching plant jalur 1-2 memiliki nilai OEE terendah pada periode Desember yaitu $50,38 \%$ hal ini dipengaruhi oleh nilai performansi yang rendah pada periode tersebut. Pada beberapa periode nilai OEE juga masih dibawah standar perusahan manufaktur kelas dunia sebesar $85 \%$, hal ini terjadi pada periode Agustus dan Desember, yaitu sebesar 69,43\% dan $50,38 \%$

Setelah dilakukan perhitungan terhadap nilai OEE pada mesin Batching plant 2 didapatkan hasil pada Tabel 9. 
Tabel 9 OEE Mesin Batching Plant 2

\begin{tabular}{ccccc}
\hline Periode & Availbility & Quality & Performance & OEE \\
\hline Juli & 0,9866 & 1 & 0,9937 & 0,9805 \\
\hline Agustus & 1 & 1 & 0,5525 & 0,5525 \\
\hline September & 1 & 1 & 0,8775 & 0,8775 \\
\hline Oktober & 1 & 1 & 0,7527 & 0,7527 \\
\hline November & 1 & 0,9987 & 0,9480 & 0,9467 \\
\hline Desember & 1 & 1 & 0,9801 & 0,9801 \\
\hline \multicolumn{5}{c}{ Rata-rata } \\
\hline
\end{tabular}

Mesin Batching plant Jalur 5-6 memiliki nilai OEE terendah pada periode Agustus yaitu sebesar 55,24\%, hal ini dipengaruhi oleh nilai performansi yang rendah pada periode tersebut. Pada beberapa periode nilai OEE juga masih dibawah standar perusahan manufaktur kelas dunia sebesar $85 \%$, hal ini terjadi pada periode Agustus dan Oktober, yaitu sebesar 55,24\% dan $75,27 \%$.

Performansi yang rendah mempengaruhi secara signifikan terhadap nilai OEE yang menjadi rendah, hal ini disebabkan produksi yang dilakukan perusahaan bukan merupakan Mass Production tetapi menggunakan sistem Job Order, dimana perusahaan hanya melakukan produksi apabila ada pesanan. Hal ini sangat mempengaruhi faktor performansi, karena target produksi awal yang dibuat perusahaan pada realisasinya tidak selalu terpenuhi.

\section{Simpulan dan Saran}

OEE pada mesin Batching plant Jalur 1-2 adalah 82,71\% dan mesin batching plant jalur 56 adalah 84,83\%, OEE kedua mesin tersebut belum memenuhi standar perusahaan manufaktur dunia. Pada beberapa periode ditemukan nilai OEE yang rendah dan dibawah standar perusahaan manufaktur dunia, ini disebabkan karena faktor performansi yang rendah karena perusahaan menggunakan sistem Job Order dimana hanya melakukan produksi apabila ada pesanan.

\section{Daftar Pustaka}

Betrianis dan Suhendra, Robby. 2005. "Pengukuran Nilai Overall Equipment Effectiveness

Sebagai Dasar Usaha Perbaikan Proses Manufaktur pada Lini produksi : Studi Kasus pada Stamping Production Division Sebuah Industri Otomotif", Jurnal Teknik Industri, Vol. 7, No. 2:91-100

Corder, Anthony.1992. Teknik Manajemen Pemeliharaan.Erlangga: Jakarta.

Dal, B., Tugewell, P. and Greatbanks, R.,2000. "Overall Equipment Effectiveness as a Measure of Operational Improvement : A Practical Analiysis". International Journal of Operation \& Production Management, Vol 20, MCB University Press, Manchester.

Hasriyono, Miko. 2009. Evaluasi Efektivitas Mesin Dengan Penerapan Total Productive Maintenance (TPM) di PT. Hadi Baru.

Mulyati, Dewi. 2011. Analisis Efektivitas Peralatan Produksi Pada PT. Bahari Dwikencana Lestari Kabupaten Aceh Tamiang.

The American Management Association, Inc. 1971. Modern Maintenance Management. Bombay.

Worsham William C. 2002. Is preventive maintenance necessary?, http://www,reliability.com/articles/article37.htm 